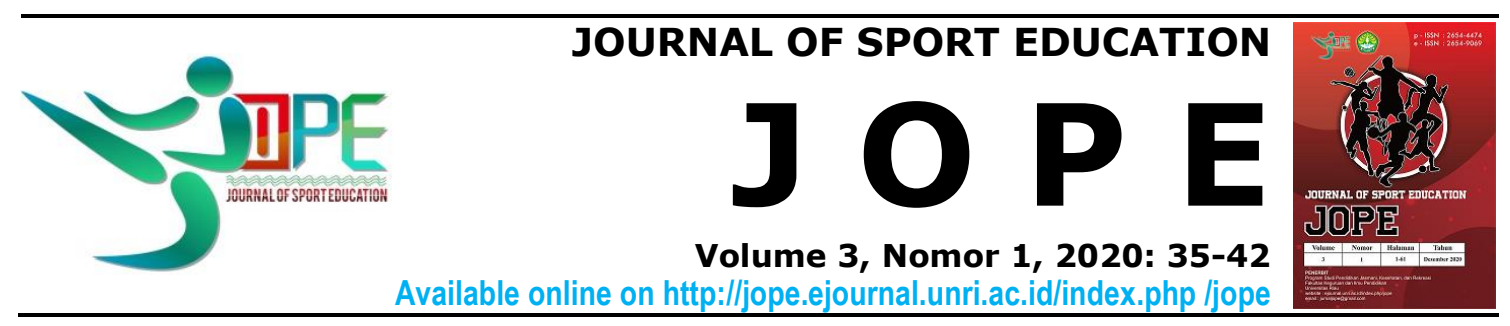

\title{
Small sided games meningkatkan kebugaran jasmani dan keterampilan bermain sepakbola
}

\author{
Mochamad Ridwan \\ Universitas Negeri Surabaya \\ mochamadridwan@unesa.ac.id
}

Received: 09 November 2020; Revised: 05 Desember 2020; Accepted: 09 Desember 2020

doi http://dx.doi.org/10.31258/jope.2.2.35-42

\begin{abstract}
Abstrak
Small sided games merupakan bagian yang tidak dapat dipisahkan dalam mengembangkan keterampilan bermain bagi pemain. Penelitian ini bertujuan untuk mengetahui dampak dari small sided games dalam meningkatkan kebugaran jasmani dan keterampilan bermain sepakbola. Metode yang digunakan adalah sistematik literatur review dengan data base google scholar, science direct, jurnal nasional serta jurnal internasional dengan rentang tahun 20182020. Hasil penelitian menunjukkan bahwa dengan small sided games dapat meningkatkan kebugaran jasmani dan keterampilan bermain sepakbola. Kebugaran jasmani dan keterampilan bermain diperlukan bagi atlet sepakbola agar penampilannya dapat sesuai dengan komponen yang harus dimiliki oleh atlet professional. Dapat disimpulkan bahwa small sided games dapat meningkatkan kebugaran jasmani dan keterampilan bermain sebagai syarat komponen yang harus dimiliki oleh pemain sepakbola. Studi literatur lainnya dapat dianalisis terkait komponen lainnya yang dapat menunjang perkembangan sepakbola menggunakan small sided games.
\end{abstract}

Kata Kunci: small sided games, kebugaran jasmani, sepakbola, atlet

\section{Small sided games improve physical fitness and football playing skills}

\begin{abstract}
Small sided games are an integral part of developing soccer skills for players. This article aims to find out the impact of small sided games in improving physical fitness and football playing skills. The method used is systematic review literature with google scholar data base, science direct, national and international journal with a range of 2012-2020. The results showed that SSG can improve physical fitness and football playing skills. Physical fitness and playing skills are required for football athletes in order for their appearance to match the components that professional athletes must have. It can be concluded that SSG can improve physical fitness and playing skills as a condition of the components that football players must have. Other literature studies can be analyzed regarding other components that can support the development of football using Small Side Games.
\end{abstract}

Keywords: small sided games, physical fitness, football, athlete

How To Cite: Ridwan, M. (2020). Small sided games meningkatkan kebugaran jasmani dan keterampilan bermain sepakbola. Journal of Sport Education (JOPE), 3 (1), 35-42 


\section{PENDAHULUAN}

Prestasi terbaik dalam cabang olahraga selalu dijadikan tolak ukur berhasilnya pembinaan olahraga. Usaha yang dilakukan pelatih untuk mencapai keberhasilan tersebut harus melalui beberapa aspek seperti fisik, teknik, taktik dan mental, oleh karena itu dibutuhkan suatu latihan guna menciptakan suatu satu kesatuan yang baik dari semua aspek tersebut (Mubarok \& Mudzakir, 2020). Hakikat latihan itu sendiri adalah suatu kebutuhan bagi seorang atlet yang dilakukan secara terencana, sistematis dan tujuan tertentu demi meningkatkan keterampilan yang dimiliki, sehingga seorang atlet akan mampu menunjukkan keterampilan terbaik dalam suatu kompetisi (Rudiana \& Prasetiyo, 2020). Beberapa penelitian telah menunjukkan bahwa kegiatan olahraga tim seperti sepak bola, bola voli, bola basket, dan bola tangan secara efektif mengurangi tekanan darah (Trajković, et al., 2020). Di era milenial saat ini, sepakbola merupakan cabang olahraga beregu yang diminati dan digemari mulai dari anak-anak, remaja, sampai dewasa (Kristianto, et al., 2020), terlepas dari faktor usia, jenis kelamin dan faktor sosial (Gema, et al., 2016). Pemain sepakbola profesional selama pertandingan resmi bisa menempuh jarak 10-12 Km, yang mana hampir $1 \mathrm{~km}$ dengan intensitas tinggi dan sekitar $200 \mathrm{~m}$ mencakup intensitas cepat, sehingga demi memenuhi tuntutan fisik yang tinggi dan dampak dari intensitas tinggi tersebut, maka seorang pelatih harus menerapkan program latihan yang sesuai dengan kondisi ketika melakukan pertandingan secara resmi, supaya para pemain bisa terbiasa berlatih dengan kondisi seperti kompetisi (Castillo, et al., 2021). Tuntutan fisik dalam sepakbola, ditandai dengan gabungan sprint pendek, lari dengan intensitas tinggi pada kecepatan yang berbeda, melompat, merebut bola, menembak dan menguasai bola di bawah tekanan dengan intensitas permainan rata-rata mulai dari 80\%-90\% denyut jantung maksimal setiap pemain (Arslan, et al., 2020). Permainan sepakbola dipengaruhi oleh ritme permainan dengan intensitas tinggi sehingga memerlukan sistem aerobik yang baik (Owen, et al., 2020). Metode yang bisa digunakan untuk meningkatkan kebugaran dan keterampilan pemain adalah Small sided games (SSG), karena SSG melibatkan pola dan jenis gerakan aktual yang banyak digunakan dalam sepakbola (Arslan, et al., 2020). Selain itu, SSG memiliki kelebihan diantaranya adalah dapat meningkatkan kapasitas daya tahan aerobik (Wardana, et al., 2018). Penerapan SSG dapat meningkatkan kinerja fisik pada pemain sepakbola remaja. Hal ini mengakibatkan peningkatan kinerja daya tahan yang lebih besar (Paul, et al., 2019). Sepakbola telah berkembang dan terintegrasi dengan jenis latihan fisik dengan staff pelatih yang umumnya memiliki tujuan untuk memaksimalkan latihan menggunakan bola. Keadaan ini untuk membenahi kaitan antara hubungan pemain dan prinsip taktik tim secara keseluruhan. Ini jelas bahwa SSG dapat digunakan untuk meningkatkan kebugaran khusus sepakbola dan faktor-faktor terkait dalam memenangkan pertandingan (Lacome, et al., 2018). SSG merupakan 


\section{Journal of Sport Education (JOPE), 3 (1) 2020 - 37}

Mochamad Ridwan

metode yang didesain dalam bentuk yang sama dengan situasi permainan sebenarnya, melibatkan seluruh pemain dalam bentuk latihan yang sesuai dengan posisi masingmasing pemain (Doewes, et al., 2020). Agar efektif, SSG perlu disesuaikan dengan karakteristik pemain, seperti ukuran lapangan, jumlah pemain, beban kerja, motivasi/instruksi pelatih, dan faktor-faktor lainnya (Sanchez et al., 2017). SSG di dalam sepakbola memiliki bentuk latihan yang bervariasi dan dirancang untuk dua tim kecil dengan menggunakan lapangan khusus yang berukuran minimalis (Wahyudianto, et al., 2020). Maka dari itu, dengan menggunakan lapangan yang kecil siswa dituntut untuk lebih lincah serta dapat mengembangkan kreativitas mereka dalam bermain. Tatanan latihan SSG juga dapat dijadikan sebagai acuan oleh guru penjas pada saat mengajar praktek, agar siswa tidak bosan ketika mengikuti pembelajaran di lapangan (Muzaffar \& Saputra, 2019). SSG telah menjadi salah satu sumber yang digunakan dalam pembelajaran yang diakui secara luas untuk mengembangkan perilaku pemain. Selain itu SSG dapat membentuk tuntutan kinematik fisik, fisiologis, teknis dan taktis dari lingkungan yang bersifat kompetitif. Dengan demikian SSG dapat membantu tujuan pembelajaran yang ingin dicapai (Coutinho et al., 2019). Dari berbagai literatur yang telah digabungkan, yang menjadi pembeda dengan penelitian-penelitian sebelumnya yaitu belum adanya systematic literature review yang membahas tentang kebugaran jasmnai dan keterampilan bermain secara bersamaan. Oleh karena itu penelitian ini bertujuan untuk mengetahui dampak dari small sided games dalam meningkatkan kebugaran jasmani dan keterampilan bermain sepakbola

\section{METODE}

Metode yang penulis gunakan adalah systematic literature review (SLR) dengan menggunakan data sekunder. Data diambil dari artikel yang terdapat di Sinta, google scholar, sciencedirect.com, springer, jurnal nasional dan jurnal internasional dengan rentang waktu yang digunakan yaitu 2 tahun yang diterbitkan sejak tahun 2018. Kata kunci yang digunakan untuk mencari artikel tersebut yaitu SSG, sepak bola, kebugaran jasmani dan keterampilan bermain. Kriteria inklusi untuk artikel ini adalah: (1) data yang relevan mengenai SSG terkait kebugaran jasmani dan keterampilan bermain; (2) peserta termasuk pemain sepak bola anakanak, remaja dan dewasa dengan tingkat amatir dan semi profesional; (3), artikel diterbitkan dalam bahasa Indonesia dan Inggris. Penelitian dikecualikan jika sampel: (1) termasuk perempuan; dan (2) tidak menyertakan data yang relevan untuk penelitian ini;

\section{HASIL DAN PEMBAHASAN}

\section{Hasil}

Berikut ini penulis berikan sebaran hasil penelitian small sided games terhadap kebugaran dan keterampilan sepakbola. Sebaran hasil penelitian tersebut selanjutnya penulis analisis untuk dijadikan sebagai sumber bahasan utama pada penelitian ini 
Journal of Sport Education (JOPE), 3 (1) 2020 - 38

Mochamad Ridwan

terkait dengan lebugaran dan keterampilan sepakbola.

Tabel 1. Sebaran Penelitian small sided games terhadap kebugaran dan keterampilan sepakbola

\begin{tabular}{|c|c|c|c|}
\hline Penulis & Sampel & Metode & Hasil \\
\hline $\begin{array}{l}\text { (Kristianto, et al., } \\
\text { 2020) }\end{array}$ & 20 orang & $\begin{array}{c}\text { Metode } \\
\text { eksperimen } \\
\text { dengan instrument } \\
\text { GPET }\end{array}$ & $\begin{array}{l}\text { SSG memberikan } \\
\text { dampak terhadap } \\
\text { keterampilan bermain } \\
\text { pemain sepakbola } \\
\text { berdasarkan tingkat } \\
\text { motor educapability } \\
\text { pemain } \\
\end{array}$ \\
\hline $\begin{array}{c}\text { (Rudiana \& Prasetiyo, } \\
\text { 2020) }\end{array}$ & 22 orang & $\begin{array}{c}\text { Metode } \\
\text { eksperimen } \\
\text { dengan instrument } \\
\text { GPAI }\end{array}$ & $\begin{array}{l}\text { SSG memberikan } \\
\text { pengaruh terhadap } \\
\text { keterampilan bermain } \\
\text { sepakbola }\end{array}$ \\
\hline (Práxedes, et al., 2018) & 19 orang & $\begin{array}{c}\text { Metode } \\
\text { eksperimen } \\
\text { dengan instrument } \\
\text { GPET }\end{array}$ & $\begin{array}{l}\text { SSG memberikan } \\
\text { pengaruh terhadap } \\
\text { pemain dalam } \\
\text { mengambil keputusan } \\
\text { dan melakukan } \\
\text { keterampilan teknik } \\
\text { passing }\end{array}$ \\
\hline $\begin{array}{c}\text { (Reinhardt, et al., } \\
\text { 2020) }\end{array}$ & 18 orang & $\begin{array}{l}\text { Field test dengan } \\
\text { instrument } \\
\text { Incremental } \\
\text { Treadmill Test } \\
\text { (ITT) }\end{array}$ & $\begin{array}{c}\text { SSG dapat membantu } \\
\text { meningkatkan kapasitas } \\
\text { daya tahan dan dapat } \\
\text { mengevaluasi } \\
\text { kemampuan spesifik } \\
\text { pemain serta } \\
\text { mengeluarkan sedikit } \\
\text { laktat }\end{array}$ \\
\hline (Bennett et al., 2018) & 73 orang & $\begin{array}{l}\text { comparative and } \\
\text { correlational } \\
\text { design dengan } \\
\text { instrument Linear } \\
\text { straight sprinting } \\
\text { test (LSST }\end{array}$ & $\begin{array}{c}\text { penggunaan SSG } \\
\text { sebagai alat untuk } \\
\text { menilai kecakapan } \\
\text { keterampilan khusus } \\
\text { sepak bola, yang dapat } \\
\text { diterapkan oleh pelatih } \\
\text { dan praktisi olahraga } \\
\text { dalam pengaturan } \\
\text { identifikasi bakat. } \\
\end{array}$ \\
\hline $\begin{array}{c}\text { (Kasanudin, et al., } \\
\text { 2020) }\end{array}$ & 20 orang & $\begin{array}{c}\text { metode } \\
\text { eksperimen } \\
\text { dengan instrument } \\
\text { performance test }\end{array}$ & $\begin{array}{c}\text { latihan SSG dapat } \\
\text { dijadikan model latihan } \\
\text { untuk meningkatkan } \\
\text { kebugaran jasmani } \\
\text { siswa dalam materi } \\
\text { ekstrakurikuler sepak } \\
\text { bola } \\
\end{array}$ \\
\hline $\begin{array}{c}\text { (Festiawan, et al., } \\
\text { 2019) }\end{array}$ & 30 orang & $\begin{array}{c}\text { Metode pre } \\
\text { eksperiment } \\
\text { dengan instrument } \\
\text { Boby Charlton test }\end{array}$ & $\begin{array}{l}\text { Latihan SSG dapat } \\
\text { meningkatkan } \\
\text { kemampuan long pass } \\
\text { siswa ekstrakurikuler }\end{array}$ \\
\hline
\end{tabular}


Journal of Sport Education (JOPE), 3 (1) 2020 - 39

Mochamad Ridwan

Lanjutan Tabel 1. Sebaran Penelitian small sided games terhadap kebugaran dan

keterampilan sepakbola

\begin{tabular}{cccc}
\hline Penulis & Sampel & Metode & Hasil \\
\hline (Asmutiar, 2016) & 36 orang & Metode & Bentuk latihan small \\
& & eksperimen & sided games Three A \\
& & dengan instrument & Sided lebih efektif \\
& & Multi Fitness Test & meningkatkan \\
& & (MFT) & cardiovaskular \\
\hline (Perdana, et al., 2017) & 24 orang & Metode & Penerapan small sided \\
& & eksperimen & games 4x4 dan 8x8 \\
& & dengan instrument & meningkatkan \\
& test keterampilan & keterampilan passing \\
& passing & atlet sepakbola \\
\hline
\end{tabular}

Hasil pengamatan mengenai penelitian yang telah dilakukan menunjukkan bahwa peningkatan yang jauh lebih besar dari beberapa keterampilan khusus yang terkait dengan olahraga tim setelah penerapan SSG dibandingkan dengan jenis latihan lain. Pelatih/guru perlu memahami karakteristik SSG yang diberikan sehingga hasil yang didapatkan sesuai dengan tujuan. Hasil ini diamati untuk kecepatan menembak, kelincahan bola tangan dan lemparan berdiri pada pemain bola tangan, kelincahan dengan bola dan kinerja pertandingan dalam sepak bola dan untuk keterampilan teknik dan menembak pada pemain voli dan basket (Hammami, et al., 2018). Banyak keuntungan yang di dapatkan dengan penggunaan SSG diantaranya mampu meningkatkan intuisi bermain dan juga teknik utama dalam permainan. Terlebih lagi sepakbola dapat dimainkan dengan tempo yang cepat (Sugandi \& Santosa, 2020). Terdapat banyak jenis permainan yang dapat diterapkan dan disesuaikan dengan kebutuhan serta keadaan, sehingga dapat maksimal dalam mencapai tujuannya. SSG memiliki dampak penting bagi pelatih karena itu berarti bahwa pemain sepak bola remaja pria dapat mengembangkan kualitas daya tahan dan keterampilan teknis secara bersamaan, sehingga mewakili pendekatan yang lebih efisien waktu untuk pelatihan. Ini menguntungkan dibandingkan dengan sifat latihan daya tahan konvensional yang relatif satu dimensi, yang hanya memungkinkan penargetan penampilan daya tahan (Moran et al., 2019). Pendekatan SSG ini penting untuk membantu menentukan validitas eksternal dan penempatan SSG sebagai alat penilaian. Meskipun kondisi SSG memiliki pengaruh minimal terkait kecakapan keterampilan, ada banyak peluang untuk terlibat dalam kondisi seperti ini untuk pemain level tinggi. Semakin banyak pemain terlibat, maka akan menimbulkan dampak aksi spesifik yang baik dalam sepakbola (Bennett et al., 2018).

\section{SIMPULAN}

SSG penting untuk diterapkan dalam latihan agar kemampuan atlet dapat berkembang sesuai dengan situasi nyata di lapangan. Banyak keuntungan jika seoarng pelatih/guru menerapkan metode ini di berbagai situasi latihan atau pembelajaran. Selain itu, SSG dapat meningkatkan level kebugaran jasmani pemain dan keterampilan bermain yang lebih 
baik. Perlu adanya penelitian lebih lanjut agar dapat tergali lebih dalam tentang keunggulan manfaat SSG.

\section{DAFTAR PUSTAKA}

Abdul Rachim Gema, Rumini, T. S. (2016). Manajemen Kompetisi Sepakbola Sumsel Super League (Ssl) Kota Palembang. Journal of Physical Education and Sport, 5(1), 2-4. https://doi.org/10.5897/JPESM

Arslan, E., Orer, G. E., \& Clemente, F. M. (2020). Running-based high-intensity interval training vs. small-sided game training programs: Effects on the physical performance, psychophysiological responses and technical skills in young soccer players. Biology of Sport, 37(2), 165-173. https://doi.org/10.5114/BIOLSPORT.20 20.94237

Asmutiar, A. (2016). Pengaruh Pelatihan Small sided games Three a Sided Dan Small sided games Six a Sided Terhadap Peningkatan Cardiovascular Endurance Pemain Sepak Bola. Jurnal Pendidikan Olahraga, 4(2), 131-143.

Bennett, K. J. M., Novak, A. R., Pluss, M. A., Stevens, C. J., Coutts, A. J., \& Fransen, J. (2018). The use of small-sided games to assess skill proficiency in youth soccer players: a talent identification tool. Science and Medicine in Football, 2(3), 231-236. https://doi.org/10.1080/24733938.2017. 1413246
Castillo, D., Raya-González, J., Sarmento, H., Clemente, F. M., \& Yanci5, J. (2021). Effects of including endurance and speed sessions within small-sided soccer games periodization on physical fitness. 291-299.

Coutinho, D., Gonçalves, B., Travassos, B., Abade, E., Wong, D. P., \& Sampaio, J. (2019). Effects of pitch spatial references on players' positioning and physical performances during football small-sided games. Journal of Sports Sciences, $\quad 37(7), \quad$ 741-747. https://doi.org/10.1080/02640414.2018. 1523671

Doewes, R. I., Purnama, S., Syaifullah, R., \& Nuryadin, I. (2020). The effect of small sided games training method on football basic skills of dribbling and passing in indonesian players aged 10-12 years. International Journal of Advanced Science and Technology, 29(3 Special Issue), 429-441.

Festiawan, R., Nurcahyo, P. J., \& Pamungkas, H. J. (2019). Pengaruh Latihan Small sided games Terhadap Kemampuan Long Pass pada Peserta Ekstrakurikuler Sepakbola. Media Ilmu Keolahragaan Indonesia, $\quad 9(1), \quad 18-22$. https://doi.org/10.15294/miki.v9i1.2066 6

Hammami, A., Gabbett, T. J., Slimani, M., \& Bouhlel, E. (2018). Does small-sided games training improve physical ftness and team-sport-specifc skills? a 
systematic review and meta-analysis.

Journal of Sports Medicine and Physical

Fitness, $\quad$ 58(10), 1446-1455.

https://doi.org/10.23736/S0022-

4707.17.07420-5

Kasanudin, Gustiawaty, R., \& Ismaya, B. (2020). Small-side game terhadap peningkatan kebugaran jasmani peserta esktrakurikuler sepak bola smpn 2 cilamaya kulon. Jurnal Literasi Olahraga, 1(August), 1-7. Retrieved from

https://journal.unsika.ac.id/index.php/JL $\mathrm{O}$

Kristianto, R., Juliantine, T., \& Nuryadi. (2020). Pengaruh Small sided games Terhadap Keterampilan Bermain Sepakbola Berdasarkan Tingkat Motor Educability. 19(1), 1-6.

Lacome, M., Simpson, B. M., Cholley, Y., Lambert, P., \& Buchheit, M. (2018). Small-sided games in elite soccer: Does one size fit all? International Journal of Sports Physiology and Performance, 13(5), 568-576. https://doi.org/10.1123/ijspp.2017-0214

Moran, J., Blagrove, R. C., Drury, B., Fernandes, J. F. T., Paxton, K., Chaabene, H., \& Ramirez-Campillo, R. (2019). Effects of Small-Sided Games vs. Conventional Endurance Training on Endurance Performance in Male Youth Soccer Players: A Meta-Analytical Comparison. Sports Medicine, (March 2019). https://doi.org/10.1007/s40279- 019-01086-w

Mubarok, M. Z., \& Mudzakir, D. O. (2020). Pengaruh Latihan Small sided games Terhadap Peningkatan Keterampilan Dribbling Pemain Sepakbola. Jurnal Pendidikan Olahraga, 9(1), 28. https://doi.org/10.31571/jpo.v9i1.1381

Muzaffar, A., \& Saputra, A. (2019). Pengaruh Latihan Small Sided Game Terhadap Akurasi Passing Pada Siswa Ekstrakulikuler Futsal Smp Negeri 1 Muaro Jambi. Indonesia Journal of Sport Science and Coaching, 1(2), 8188.

https://doi.org/ttps://doi.org/10.22437/ijs sc.v1i2.7605

Owen, A. L., Newton, M., Shovlin, A., \& Malone, S. (2020). The Use of SmallSided Games as an Aerobic Fitness Assessment Supplement within Elite Level Professional Soccer. Journal of Human Kinetics, 71(1), 243-253. https://doi.org/10.2478/hukin-20190086

Paul, D. J., Marques, J. B., \& Nassis, G. P. (2019). The effect of a concentrated period of soccer-specific fitness training with small-sided games on physical fitness in youth players. Journal of Sports Medicine and Physical Fitness, $59(6)$, 962-968. https://doi.org/10.23736/S00224707.18.08547-X

Perdana, D. S., Sudjana, I. N., \& Januarto, O. B. (2017). Pengaruh Latihan Small sided 
games 4X4 Dan 8X8 Terhadap

Peningkatan Keterampilan Passing Pada

Pemain Sepakbola Ekstrakurikuler Smp

Negeri 2 Grati Kabupaten Pasuruan.

Gelanggang Pendidikan Jasmani

Indonesia,

l(1),

40.

https://doi.org/10.17977/um040v1i1p40-

55

Práxedes, A., Moreno, A., Gil-Arias, A., Claver, F., \& Villar, F. Del. (2018). The effect of small-sided games with different levels of opposition on the tactical behaviour of young footballers with different levels of sport expertise. PLoS ONE, 13(1), 1-14. https://doi.org/10.1371/journal.pone.019 0157

Reinhardt, L., Schulze, S., Kurz, E., \& Schwesig, R. (2020). An Investigation into the Relationship Between Heart Rate Recovery in Small-Sided Games and Endurance Performance in Male, Semi-professional Soccer Players. Sports Medicine - Open, 6(1). https://doi.org/10.1186/s40798-02000273-8

Rudiana, R. D. P., \& Prasetiyo, A. F. (2020). Pengaruh Latihan Small Side Games Terhadap Keterampilan Bermain Bola. 6(1), 132-137.

Sanchez-Sanchez, J., Hernández, D., Casamichana, D., Martínez-Salazar, C., Ramirez-Campillo, R., \& Sampaio, J. (2017). Heart rate, technical performance, and session-RPE in elite youth soccer small-sided games played with wildcard players. Journal of Strength and Conditioning Research, $31(10)$, 2678-2685. https://doi.org/10.1519/JSC.0000000000 001736

Sugandi, G., \& Santosa, A. (2020). Pengaruh small sided game terhadap keterampilan teknik dasar passing dalam permainan futsal. 2(1), 109-116.

Trajković, N., Sporiš, G., Krističević, T., \& Bogataj, Š. (2020). Effects of smallsided recreational volleyball on health markers and physical fitness in middleaged men. International Journal of Environmental Research and Public Health, 17(9). https://doi.org/10.3390/ijerph17093021

Wahyudianto, M. Z., Setiawan, I., \& Pratama, B. A. (2020). Pengaruh Latihan Small Side Game Tipe Intermitten Terhadap Kapasitas Aerobik Di Sekolah Sepakbola Satria Muda Lamongan. SPRINTER: Jurnal Ilmu Olahraga, l(1), 72-78.

Wardana, C. R., Setiabudi, M. A., Candra, A. T., \& Kesehatan, O. (2018). Pengaruh Latihan Small-Sided Games Terhadap Keterampilan Passing, Controlling dan Shooting Peserta Ekstrakurikuler Sepakbola SMK Negeri 1 Tegalsari Kabupaten Banyuwangi. Kejaora, 3(November), 194-201. 